\title{
Uso de Micofenolato Mofetil em Pacientes com Lúpus Eritematoso Sistêmico Juvenil e Nefrite Refratária ${ }^{(*)}$
}

\section{Use of Mycophenolate Mofetil in Patients with Juvenile Systemic Lupus Erythematosus and Refractory Nephritis}

\author{
Ricardo Maisse Suehiro ${ }^{(1)}$, Bernadete Lourdes Liphaus ${ }^{(2)}$, Mércia Moreira Facó ${ }^{(1)}$, \\ Lúcia Maria Mattei Arruda Campos ${ }^{(2)}$ e Clovis Artur Almeida Silva ${ }^{(3)}$
}

\section{RESUMO}

O micofenolato mofetil (MFM) é uma droga imunossupressora utilizada no tratamento de doenças auto-imunes, incluindo o lúpus eritematoso sistêmico juvenil, particularmente nos casos de nefrite lúpica refratária à terapia com corticosteróides, ciclofosfamida, azatioprina, metotrexato e/ou ciclosporina. Relatamos a eficácia e os eventos adversos do MFM em quatro pacientes com nefrite lúpica refratária. Os pacientes foram acompanhados por um período de 2,1 a 11,1 anos (média de 6,8 anos) e tratados com MFM na dose de 1 a 3g/dia por um período de 3 a 36 meses (média de 13,75 meses). Dois pacientes (um classe histológica renal IV e outro classe V) responderam ao tratamento com MFM e apresentaram melhora da proteinúria de $24 \mathrm{~h}$. A melhor resposta ocorreu na paciente com classe $\mathrm{V}$, como é descrito na literatura. Dois pacientes não obtiveram resposta (um classe III e um classe IV) e evoluíram para insuficiência renal aguda, um deles com manutenção da proteinúria nefrótica. Não foram observados eventos adversos. O MFM pode ser uma alternativa terapêutica em pacientes juvenis com nefrite lúpica refratária, particularmente nas classes histológicas renais V e IV.

Palavras-chave: lúpus eritematoso sistêmico, nefrite, micofenolato mofetil, crianças e adolescentes.

\section{INTRODUÇÃO}

O lúpus eritematoso sistêmico juvenil (LESJ) é uma doença auto-imune sistêmica com incidência média anual de 0,36

\begin{abstract}
The mycophenolate mofetil (MMF) is an immunosuppressive drug used in the treatment of autoimmune diseases including juvenile systemic lupus erythematosus, especially in cases of lupus nephritis refractory to treatment with corticosteroids, cyclophosphamide, azathioprine, methotrexate and/or cyclosporine. This paper describes the efficacy and adverse events of $M M F$ in four patients with refractory lupus nephritis. The patients were followed up for 2,1 to 11,1 years (mean 6,8 years) and treated with a MMF dose of 1 to $3 \mathrm{~g} /$ day for a period of 3 to 36 months (mean 13,75 months). Two patients (one with renal histologic class $I V$ and another with class $V$ ) presented an improvement with a decrease in the $24 \mathrm{~h}$ proteinuiria. The best efficacy was observed in the patient with class $V$, as described in literature. Two patients did not respond (one class III and other class IV) and they presented acute renal failure, one of them continued with nephrotic proteinúria. Adverse events were not observed. MMF can be an alternative therapy for juvenile patients with refractory lupus nephritis, especially in cases of renal histologic classes $V$ and IV.
\end{abstract}

Keywords: systemic lupus erythematosus, nephritis, mycophenolate mofetil, children and adolescents.

a 0,6 caso por 100.000 habitantes $^{(1)}$. A nefrite lúpica é evidente, clínica ou laboratorialmente, em pelo menos $75 \%$ dos pacientes, mas histologicamente está presente em praticamente $100 \%$ dos casos. As alterações histológicas renais

\footnotetext{
Unidade de Reumatologia Pediátrica, Instituto da Criança do Hospital das Clínicas da Faculdade de Medicina da Universidade de São Paulo (ICr-HC-FMUSP), São Paulo-SP, Brasil. Recebido em 5/2/2004. Aprovado, após revisão, em 11/5/2004.

1. Médico(a) complementando(a) da Unidade de Reumatologia Pediátrica do ICr-HC-FMUSP.

2. Mestre em Medicina pela FMUSP e Médica Assistente da Unidade de Reumatologia Pediátrica do ICr-HC-FMUSP.

3. Doutor em Medicina pela FMUSP e Chefe da Unidade de Reumatologia Pediátrica do ICr-HC-FMUSP.

Endereço para correspondência: Bernadete de Lourdes Liphaus. Unidade de Reumatologia do Instituto da Criança do Hospital das Clínicas da Faculdade de Medicina da Universidade de São Paulo (ICr-HC-FMUSP), Av. Dr. Enéas de Carvalho Aguiar, 647 - 7. ${ }^{\circ}$ andar, CEP 05403-900, São Paulo-SP, Brasil. E-mail: bernadll@icr.hcnet.usp.br
} 
de pior prognóstico são a glomerulonefrite proliferativa difusa (GNPD), classe IV da OMS, glomerulonefrite proliferativa focal (GNPD), classe III da OMS, e a glomerulonefrite membranosa (GM), classe V da OMS. Pacientes que apresentam GM podem desenvolver síndrome nefrótica com proteinúria persistente e risco aumentado de eventos cardiovasculares, enquanto os pacientes com GNPD podem evoluir para doença renal terminal e/ou óbito ${ }^{(2,3,4)}$.

O tratamento convencional da GNPD em pacientes com LESJ inclui corticosteróides, freqüentemente em combinação com drogas imunossupressoras, como a azatioprina ou a ciclofosfamida. O tratamento da GM é controverso, incluindo vários esquemas: monoterapia com corticosteróides ou em combinação com ciclosporina, ciclofosfamida, azatioprina e/ou clorambuci ${ }^{(5,6,7,8)}$.

O micofenolato mofetil (MFM) é uma droga imunossupressora utilizada em transplantes de órgãos e está sendo utilizada no tratamento de doenças auto-imunes, incluindo o LESJ, particularmente nos casos de nefrite lúpica refratária ${ }^{(9)}$.

Relatamos os casos de quatro pacientes com LESJ e nefrite refratária (um classe histológica renal III, dois classe IV e um classe V), acompanhados na Unidade de Reumatologia do Instituto da Criança do HC-FMUSP por um período de 2,1 a 11,1 anos (média de 6,8 anos) e tratados com MFM na dose de $1 \mathrm{a} 3 \mathrm{~g} /$ dia por um período de 3 a 36 meses (média de 13,74 meses). A idade média dos pacientes no início do tratamento com MMF foi de 19,5 anos. Foram avaliados os seguintes parâmetros: Systemic Lupus Erythematosus Disease Activity Index (SLEDAI) ${ }^{(10)}$, proteinúria de 24 horas, velocidade de hemossedimentação (VHS), uréia e creatinina séricos, antes e após o tratamento com MMF, conforme evidenciado na Tabela 1.

\section{RELATO DOS CASOS}

\section{CASO 1}

A.C.M., sexo feminino, 17 anos de idade, com diagnóstico de LESJ desde os 12 anos, quando apresentou quadro de anasarca, proteinúria de $4,89 \mathrm{~g} / 24 \mathrm{~h}$ e FAN positivo. Em agosto de 2001 a prednisona foi utilizada na dose de $2 \mathrm{mg} /$ $\mathrm{kg} /$ dia, sem controle da doença com manutenção da proteinúria nefrótica. Em setembro de 2001 foi associada pulsoterapia com ciclofosfamida. Em outubro de 2001, a biópsia renal foi realizada e evidenciou GNPD. Em março de 2002 a paciente apresentava atividade renal e artrite (SLEDAI 12), sendo associado metotrexato $\left(10 \mathrm{mg} / \mathrm{m}^{2} / \mathrm{semana}\right)$. A pulsoterapia com ciclofosfamida foi suspensa em novembro de 2002 (após a $8^{\text {a }}$ infusão) por múltiplas infecções (otite, diarréia persistente, paroníquia em segundo quirodáctilo esquerdo e broncopneumonia). Em dezembro de 2002 houve aumento da proteinúria $(6,6 \mathrm{~g} / 24 \mathrm{~h})$, tendo sido associados a pulsoterapia com metilprednisolona e o MFM (1g/dia) ao metotrexato. Em janeiro de 2003 o MFM foi aumentado para $2 \mathrm{~g}$ /dia por manutenção da proteinúria $(3,25 \mathrm{~g} / 24 \mathrm{~h})$. A paciente evoluiu com piora importante da proteinúria $(14,2 \mathrm{~g} / 24 \mathrm{~h})$, sendo aumentado o MFM para $3 \mathrm{~g} /$ dia, com melhora progressiva da proteinúria. Em outubro de 2003 a paciente estava em uso de prednisona $20 \mathrm{mg} /$ dia, cloroquina $250 \mathrm{mg} /$ dia e micofenolato mofetil $3 \mathrm{~g} /$ dia, sem edema e com proteinúria de $2,23 \mathrm{~g} / 24 \mathrm{~h}$.

\section{CASO 2}

L.S.S., sexo feminino, 21 anos de idade, com diagnóstico de LESJ desde os 10 anos, quando apresentou eritema malar, pericardite, pleurite, FAN 1/200 homogêneo, anti-DNA positivo e proteinúria. Em abril de 1993 foi iniciado trata-

TABELA 1

CARACTERÍSTICAS LABORATORIAIS, HISTOLÓGICAS E TRATAMENTO PRÉVIO DE QUATRO PACIENTES COM NEFRITE LÚPICA JUVENIL REFRATÁRIA QUE RECEBERAM MICOFENOLATO MOFETIL

\begin{tabular}{cccccccc}
\hline Paciente & $\begin{array}{c}\text { CHR ( OMS) } \\
\text { anteriores }\end{array}$ & $\begin{array}{c}\text { Tratamentos } \\
\text { Início/ Final }\end{array}$ & $\begin{array}{c}\text { SLEDAI } \\
\text { Início/ Final }\end{array}$ & $\begin{array}{c}\text { Proteinúria 24h } \\
\text { Início/Final }\end{array}$ & $\begin{array}{c}\text { VHS } \\
\text { Início/Final }\end{array}$ & $\begin{array}{c}\text { Uréia } \\
\text { Início/Final }\end{array}$ & $\begin{array}{c}\text { Creatinina } \\
22 / 20\end{array}$ \\
\hline 1 & IV & $\mathrm{Pd} / \mathrm{CF} / \mathrm{M} / \mathrm{A}$ & $12 / 08$ & $6,60 / 2,23$ & $58 / 36$ & $0,55 / 0,60$ \\
\hline 2 & $\mathrm{~V}$ & $\mathrm{Pd} / \mathrm{CF} / \mathrm{A} / \mathrm{CP}$ & $12 / 04$ & $6,18 / 0,14$ & $25 / 12$ & $55 / 41$ & $1,74 / 0,68$ \\
3 & III & $\mathrm{Pd} / \mathrm{CQ} / \mathrm{A}$ & $20 / 16$ & $2,25 / 3,59$ & $40 / 56$ & $11 / 45$ & $0,85 / 1,35$ \\
4 & $\mathrm{IV}$ & $\mathrm{Pd} / \mathrm{CQ} / \mathrm{CF} / \mathrm{A} / \mathrm{M} / \mathrm{MP}$ & $14 / 12$ & $2,55 / 1,64$ & $30 / 39$ & $32 / 173$ & $0,60 / 1,40$ \\
\hline
\end{tabular}

$\mathrm{A}=$ azatioprina; CHR (OMS) = classe histológica renal segundo a classificação da OMS para nefrite lúpica; CF = pulsoterapia com ciclofosfamida; CP = ciclosporina; CQ = cloroquina; Creatinina em $\mathrm{mg} / \mathrm{dl} ; \mathrm{M}=$ metotrexato; $\mathrm{MP}=$ pulsoterapia com metilprednisolona; $\mathrm{Pd}=$ prednisona; Uréia em $\mathrm{mg} / \mathrm{dl}$; VHS = velocidade de hemossedimentação em mm $1^{\text {a }}$ hora. 
mento com prednisona 2mg/kg/dia. Em agosto de 1993 evoluiu com piora da função renal (uréia $80 \mathrm{mg} / \mathrm{dl}$ e creatinina $1,2 \mathrm{mg} / \mathrm{dl}$ ) e proteinúria de $2,7 \mathrm{~g} / 24 \mathrm{~h}$. A biópsia renal mostrou GM e em novembro de 1993 foi iniciado pulsoterapias com ciclofosfamida e metilprednisolona (total de 13 infusões). Em novembro de 1996 a paciente evoluiu com piora importante da proteinúria até $14,17 \mathrm{~g} / 24 \mathrm{~h}$. A ciclofosfamida foi suspensa e foi associada azatioprina à corticoterapia. Em novembro de 1998 a azatioprina foi substituída por ciclosporina em razão da manutenção da proteinúria $(5,67 \mathrm{~g} / 24 \mathrm{~h})$. A partir de fevereiro de 1999 , em uso de ciclosporina $(5 \mathrm{mg} / \mathrm{kg} /$ dia $)$ e corticosteróide $(10 \mathrm{mg} / \mathrm{dia})$, apresentou melhora da proteinúria $(2,2 \mathrm{~g} / 24 \mathrm{~h})$. No entanto, em outubro de 2000 observou-se elevação progressiva da proteinúria $(6,18 \mathrm{~g} / 24 \mathrm{~h})$, edema de membros inferiores, hipoalbuminemia $(1,8 \mathrm{~g} / \mathrm{dl})$ e vasculites. Nesta ocasião não havia comprometimento de outros órgãos ou sistemas, sendo optado pela substituição da ciclosporina pelo MFM $(1 \mathrm{~g} / \mathrm{dia})$, associado a prednisona $2 \mathrm{mg} / \mathrm{kg} / \mathrm{dia} . \mathrm{Em}$ novembro de 2000 houve diminuição considerável da proteinúria $(2,4 \mathrm{~g} / 24 \mathrm{~h})$ e normalização em janeiro de 2001. Em março de 2003, dois anos e cinco meses após a introdução do MFM (1g/dia), foi possível a redução da corticoterapia (10mg de prednisona) e a proteinúria mantinha-se em $0,14 \mathrm{~g} / 24 \mathrm{~h}$.

\section{CASO 3}

R.D.N., sexo feminino, 18 anos de idade, com diagnóstico de LESJ desde os 14 anos, quando iniciou quadro de pericardite, pleurite, artrite, linfopenia, FAN e anti-DNA positivos. Em novembro de 1998 foi introduzida inicialmente prednisona $1 \mathrm{mg} / \mathrm{kg} /$ dia. Em março de 2001, em razão da persistência do comprometimento cutâneo e alopecia, foi associada hidroxicloroquina. Em abril de 2001 a paciente apresentou piora da função renal e presença de proteinúria $(1,15 \mathrm{~g} / 24 \mathrm{~h})$, sendo associada azatioprina. Em julho de 2001 foi realizada biópsia renal que mostrou GNPF e a dose da azatioprina foi aumentada para $3 \mathrm{mg} / \mathrm{kg} / \mathrm{dia}$, em razão da piora da proteinúria $(3,46 \mathrm{~g} / 24 \mathrm{~h})$. Como a paciente mantinha proteinúria há oito meses, em dezembro de 2001, optou-se por suspender a azatioprina e introduzir MFM na dose de $1 \mathrm{~g} /$ dia. Em janeiro de 2002 o MFM foi aumentado para $2 \mathrm{~g} /$ dia, pois a paciente apresentava proteinúria de 2,77g/24h. Em março de 2002 a paciente evoluiu com insuficiência renal aguda (uréia $45,4 \mathrm{mg} / \mathrm{dl}$ e creatinina $1,35 \mathrm{mg} / \mathrm{dl})$ e piora da proteinúria $(3,59 \mathrm{~g} / 24 \mathrm{~h})$. O MFM (2g/dia) foi suspenso e iniciadas pulsoterapias com metilprednisolona (seis infusões mensais por três dias) e ciclofos- famida (recebeu três infusões mensais). Em julho de 2002 a paciente foi internada com insuficiência cardíaca congestiva, evoluindo com piora da insuficiência renal (uréia $156 \mathrm{mg} / \mathrm{dl}$, creatinina $2,95 \mathrm{mg} / \mathrm{dl}$ ). Submetida a plasmaférese por três dias, com piora progressiva da função renal (uréia $200 \mathrm{mg} / \mathrm{dl}$ e creatinina $4,0 \mathrm{mg} / \mathrm{dl}$ ), iniciada hemodiálise por três dias e, após, diálise peritonial. Evoluiu com febre, broncopneumonia, peritonite bacteriana e choque séptico com isolamento de Staphylococcus aureus e Stretrophomonas malthophyla, necessitando de vários antimicrobianos (vancomicina, meropenem; linezolida e sulfametoxazoltrimetropin). Uma semana após a introdução de linezolida e sulfametoxazol-trimetropin evoluiu com síndrome de Stevens-Johnson, tendo sido utilizada a gamaglobulina endovenosa. Em agosto de 2002 evoluiu para óbito com hemorragia pulmonar e vasculites. A necrópsia mostrou achados compatíveis com atividade e infecção generalizada (broncopneumonia, abscessos cerebrais e peritonite purulenta).

\section{CASO 4}

T.R.P., sexo masculino, 22 anos de idade, com diagnóstico de LESJ desde os 10 anos, quando iniciou quadro de artrite, eritema malar, pleurite, hematúria, proteinúria $(2,55 \mathrm{~g} / 24 \mathrm{~h})$, FAN e anti-DNA positivos. Em agosto de 1992 foi introduzida terapia com prednisona e cloroquina e realizada biópsia renal que mostrou GNPD. Em setembro de 1992 foi iniciada pulsoterapia com ciclofosfamida (sete pulsos na fase indução, dois na fase de manutenção e recebeu reindução com mais três pulsos). Este paciente apresentou leucopenia e várias infecções na reindução com a pulsoterapia de ciclofosfamida (sinusites e broncopneumonias), sem controle da atividade da doença. Em janeiro de 1994 a ciclofosfamida foi suspensa e introduzida a azatioprina por aumento da proteinúria $(4,19 \mathrm{~g} / 24 \mathrm{~h})$. Em fevereiro de 1994 foi utilizada pulsoterapia com metilprednisolona em razão da manutenção da proteinúria $(3,54 \mathrm{~g} / 24 \mathrm{~h})$. Em março de 1994 mantinha proteinúria $(4,9 \mathrm{~g} / 24 \mathrm{~h})$, sendo associado metotrexato à azatioprina e à prednisona. $\mathrm{O}$ paciente evoluiu com melhora progressiva da proteinúria, a qual normalizou em agosto de 1994. A azatioprina e o metotrexato foram suspensos, respectivamente em maio e outubro de 1998. Porém, em dezembro de 1998, o paciente evoluiu com quadro de insuficiência renal aguda (uréia $472 \mathrm{mg} / \mathrm{dl}$ e creatinina $1,4 \mathrm{mg} / \mathrm{dl})$ e proteinúria $(2,55 \mathrm{~g} / 24 \mathrm{~h})$, tendo sido submetido a três sessões de plasmaférese e introduzido MFM (inicialmente $1 \mathrm{~g} /$ dia, aumentado progressivamente até $2 \mathrm{~g} / \mathrm{dia}$ ) associado à prednisona, com 
normalização da função renal em maio de 1998. Em junho de 1999 apresentou novo episódio de insuficiência renal aguda (uréia $173 \mathrm{mg} / \mathrm{dl}$ e creatinina $4,5 \mathrm{mg} / \mathrm{dl}$ ), sendo suspenso o MFM ( $2 \mathrm{~g} / \mathrm{dia})$. O paciente foi submetido a três sessões de plasmaférese e realizados pulsos mensais de metilprednisolona. Em fevereiro de 2001, em razão da manutenção da proteinúria $(0,7 \mathrm{~g} / 24 \mathrm{~h})$, foi realizada nova biópsia renal que mostrou GM e introduzida ciclosporina. Em agosto de 2001, seis meses após a introdução da ciclosporina, evoluiu com remissão clínica e laboratorial.

\section{DISCUSSÃO}

A doença renal é a principal causa de morbimortalidade no $\operatorname{LESJ}^{(11,12)}$. A GNPD e a GM são as classes histológicas renais que apresentam pior prognóstico ${ }^{(13-15)}$. Pacientes com LES de início na idade adulta e com GM podem desenvolver síndrome nefrótica com proteinúria persistente e/ou risco aumentado de eventos cardiovasculares, porém seu tratamento permanece controverso: monoterapia com corticosteróides ou em combinação com imunossupressores. Por sua vez na GNPD, os esquemas terapêuticos que incluem ciclofosfamida e corticosteróide são os mais efetivos, apesar de sua alta toxicidade ${ }^{(16,17)}$. Aproximadamente 5\% a 15\% dos pacientes com GNPD são refratários ao tratamento com ciclofosfamida ${ }^{(18-21)}$ e 30\% a 50\% desenvolvem insuficiência renal ou doença renal terminal após cinco anos de doença ${ }^{(22-23)}$. Além disso, infertilidade e infecções relacionadas com a ciclofosfamida são duas grandes preocupações ${ }^{(24-27)}$.

Com relação ao tratamento da nefrite do LESJ, a maioria dos estudos é aberta, com pequenas casuísticas e baseados nas experiências prospectivas dos serviços de reumatologia pediátrica. Os corticosteróides constituem a primeira escolha de tratamento, com altas doses de prednisona/ prednisolona ou com pulsoterapia com metilprednisolona. Os imunossupressores mais utilizados para as classes histológicas renais III, IV ou V são ciclofosfamida (pulsos), azatioprina e/ou ciclosporina ${ }^{(1)}$.

Entre as novas estratégias de tratamento, o MFM, utilizado amplamente em transplantes de órgãos, tem se mostrado eficaz em doenças auto-imunes como dermatomiosite, LES, nefropatia por IgA, psoríase, vasculite sistêmica, pênfigo, anemia hemolítica, doença inflamatória intestinal, uveíte refratária, doença enxerto-versus-hospedeiro e síndrome hemolítico-urêmica ${ }^{(28-33)}$.

O ácido micofenólico, metabólito ativo do MFM, inibe seletivamente a proliferação de linfócitos T e B, a formação de anticorpos e a glicosilação de moléculas de adesão pela inibição da síntese de nucleotídeos de purina e depleção de trifosfato de guanosina de linfócitos e monócitos ${ }^{(34-36)}$. Desta forma, o ácido micofenólico reduz o recrutamento de linfócitos e monócitos aos sítios de inflamação, contribuindo para sua ação imunossupressora em doenças autoimunes e rejeição de transplantes ${ }^{(37)}$.

O ácido micofenólico também inibe a proliferação de outros tipos celulares como as células mesangiais de ratos e humanos ${ }^{(38)}$. Em um modelo animal de GNPD, o tratamento com MFM diminuiu significativamente a hipercelularidade glomerular, a gravidade do dano histológico, a deposição de matriz extracelular e a proteinúria, sugerindo que a inibição da proliferação mesangial é um dos principais efeitos da $\operatorname{droga}^{(39)}$.

A maioria dos estudos publicados sobre o uso do MFM em nefrite lúpica é retrospectiva, não controlada, envolvendo um pequeno número de pacientes e geralmente adultos.

Dooley et al. ${ }^{(40)}$ estudaram 13 pacientes (16 a 48 anos) com nefrite lúpica refratária (12 com classe histológica renal IV e um classe V da OMS) tratados com MFM (0,5 a 2,0g/ dia) associado a prednisona por um período médio de 12,9 meses. A função renal e a proteinúria melhoraram significantemente e alguns pacientes também apresentaram melhora dos níveis séricos de complemento (C3) e de antiDNA. Eventos adversos incluíram estomatite herpética, associada a leucopenia grave, leucopenia assintomática, náuseas, diarréia, pancreatite e pneumonia sem leucopenia.

Chan et al. ${ }^{(41)}$, em um estudo prospectivo, randomizado, controlado, compararam a eficácia do MFM (1-2g/dia) e prednisolona (grupo 1) com ciclofosfamida via oral e prednisolona, seguido por azatioprina e prednisolona (grupo 2). Foram estudados 42 pacientes adultos com GNPD, sendo que $81 \%$ dos 21 pacientes tratados com MFM e prednisolona apresentaram remissão completa e $14 \%$ apresentaram remissão parcial, comparado a $76 \%$ e $14 \%$ dos 21 pacientes do grupo 2. Infecções foram observadas em 19\% dos pacientes do grupo 1 e em $33 \%$ do grupo 2. Diarréia severa ocorreu apenas em um paciente do grupo 1. Outros eventos adversos ocorreram apenas no grupo 2: amenorréia (23\%), alopecia (19\%), leucopenia $(10 \%)$ e óbito $(10 \%)$. Cabe ressaltar que a boa eficácia do MFM foi evidenciada em uma população de pacientes lúpicos com função renal preservada.

No estudo de Petri ${ }^{(42)}$, contudo, dos dez pacientes adultos com nefrite lúpica e proteinúria nefrótica tratados com MFM, nenhum evoluiu com remissão completa (proteinúria $<1,0 \mathrm{~g} /$ $24 \mathrm{~h}$ ), embora tenham apresentado melhora da atividade clínica (SLEDAI) e dos níveis séricos de anti-DNA. 
Briggs et al. ${ }^{(43)}$ estudaram oito casos de adultos com síndrome nefrótica ou insuficiência renal (três pacientes com GM, dois com lesões mínimas, um com glomeruloesclerose segmentar e focal e dois com nefrite lúpica) tratados com MFM $(0,75$ a 1,0g/dia), como monoterapia ou em combinação com doses baixas de corticosteróide. Houve redução significativa da proteinúria e/ou estabilização da função renal, sendo possível a retirada do corticóide nos pacientes que não apresentavam lúpus. O MFM foi bem tolerado, sem evidências de toxicidade.

Figueiredo et al. ${ }^{(4)}$ acompanharam 20 adultos com nefrite lúpica (12 pacientes com GM) tratados com MFM durante um ano, em associação com prednisona (100\%) e azatioprina (70\%). Quatro pacientes haviam recebido ciclofosfamida anteriormente. Resposta parcial (redução da proteinúria em pelo menos $50 \%$ ) foi obtida em todos os pacientes, com redução da dose de prednisona e aumento de albumina sérica. Resposta total (proteinúria $<0,3 \mathrm{~g} / 24 \mathrm{~h}$ ) foi obtida em 11 pacientes $(55 \%)$ e recidivas (piora da proteinúria ou da função renal) foram observadas em três pacientes (15\%).

A dose do MFM para doenças auto-imunes ainda é controversa. Em nossos pacientes, a dose inicial utilizada foi de $1 \mathrm{~g} /$ dia, dividida em duas tomadas, como na maioria dos estudos, chegando a $3 \mathrm{~g} /$ dia.

Existe apenas um estudo multicêntrico aberto, na faixa etária pediátrica, com o uso de MFM na nefrite lúpica. Neste estudo, Buratti et al. ${ }^{(4)}$ avaliaram 11 adolescentes (idades entre 13,3 e 17,0 anos) com nefrite lúpica refratária tratados com MFM (dose média de 1g/dia) durante 9,8 meses. Todos os pacientes receberam prednisona e sete estavam em uso de hidroxicloroquina. A função renal normalizou nos quatro pacientes com $\mathrm{GM}$, mas não houve melhora nos quatro pacientes com GNPD. Eventos adversos foram observados em 73\% dos pacientes e incluíram infecções, leucopenia, náuseas, prurido, cefaléia e fadiga.

Gesteira e Montane ${ }^{(46)}$ estudaram 13 pacientes pediátricos (idade média de início da doença de 12,5 anos) com GNPD que receberam seis pulsos mensais de ciclofosfamida (500 a $\left.1000 \mathrm{mg} / \mathrm{m}^{2} / \mathrm{mês}\right)$, seguidos por MFM $\left(250-500 \mathrm{mg} / \mathrm{m}^{2}\right)$, dose máxima de $1 \mathrm{~g} /$ dia, acompanhados por um período médio de cinco anos. Todos foram mantidos em uso de prednisona 5 a $10 \mathrm{mg} /$ dia e hidroxicloroquina $200 \mathrm{mg}$ /dia. Dois pacientes permaneceram com proteinúria em níveis nefróticos e evoluíram para doença renal terminal em dois anos. Nos demais pacientes houve redução estatisticamente significante dos níveis de proteinúria, aumento dos níveis séricos de albumina e aumento do clearance de creatinina. Seis pacientes permaneceram em remissão por mais de cinco anos. Dois pacientes apresentaram herpes zoster, dois infecção por citomegalovírus, dois pneumonias bacterianas, um varicela e um meningite tuberculosa.

$\mathrm{Fu} \mathrm{e} \mathrm{Liu}^{(47)}$ relataram duas crianças lúpicas (uma com sete e outra com doze anos de idade) com GNPD não responsivas ao tratamento com ciclofosfamida e ciclosporina, que responderam satisfatoriamente ao tratamento com MFM.

De nossos casos, duas pacientes responderam ao MFM: uma nefrite lúpica classe IV (caso 1) e outra classe V (caso 2). A resposta mais rápida e eficaz ocorreu na paciente com classe $\mathrm{V}$, assim como observado por Buratti et al. ${ }^{(45)}$. O paciente com GNPD (caso 1) apresentou resposta parcial, com melhora significativa da proteinúria de 24 horas.

No entanto, a paciente com GNPF (caso 3) evoluiu com piora da proteinúria e insuficiência renal três meses após introdução do MFM e o outro paciente com GNPD (caso 4) apresentou melhora inicial da proteinúria, mas após seis meses de uso do MFM evoluiu com insuficiência renal, sendo necessária sua suspensão.

Quanto aos eventos adversos, não observamos alterações clinicas ou laboratoriais relacionadas com o MFM.

A opção do uso de imunossupressores para a nefrite do LESJ foi individualizada para cada paciente de acordo com a literatura médica, experiência anterior do nosso grupo e disponibilidade do medicamento no momento da sua introdução. A terapêutica na nefrite do LESJ ainda permanece controversa. A maioria dos estudos indica o uso de corticosteróide associado à pulsoterapia com ciclofosfamida na GNPD $^{(1,4,7,48)}$, como utilizado nos casos 1 e 4 . Por sua vez, alguns autores canadenses sugerem a azatioprina como a droga imunossupressora preferencial na nefrite lúpica (Classe histológicas II, III, IV ou V $)^{(49)}$. Neste estudo evidenciou-se uma sobrevida de $94 \%$ com 11 anos de seguimento.

O tratamento permanece controverso nas nefrites GNPF e GM, permitindo o uso isolado de corticóide ou em combinação com os diversos imunossupressores (azatioprina, ciclosporina, metotrexato e MFM) utilizados de acordo com a experiência de cada centro. Recentemente, a pulsoterapia com ciclosfosfamida tem também sido indicada no tratamento inicial da GNPF no LESJ ${ }^{(48)}$.

Em nossa Unidade de Reumatologia Pediátrica, o MFM é indicado nas nefrites refratárias aos corticosteróides, via oral ou endovenosa, à pulsoterapia com ciclofosfamida, à azatioprina e ciclosporina e particularmente nos pacientes com GM. Nos pacientes pediátricos com nefrite lúpica refratária, estudos clínicos prospectivos controlados são necessários para comprovar a eficácia do MFM. 


\section{REFERÊNCIAS}

1. Cassidy JT, Petty RE: Systemic Lupus Erythematosus. In: Textbook of Pediatric Rheumatology, 4th ed, Philadelphia, WB Saunders Co 397, 2001.

2. Donadio JV, Hart GM, Bergstrahl EJ, et al: Prognostic determinations in lupus nephritis: a long-term clinicopathologic study. Lupus 4: 109-15, 1995.

3. Grahan TB, Lovell DJ: Outcome in pediatric rheumatic disease. Curr Opin Rheumatol 9:434-9, 1997.

4. Cameron JS: Lupus nephritis in childhood and adolescence. Pediatr Nephrol 8:230-49, 1994.

5. Valeri A, Radhakrishana J, Estes D, D’Ágati V, Pirani C, Appel GB: Intravenous pulse cyclophosphamide treatment of severe lupus nephritis: a prospective five-year study. Clin Nephrol 42:71-8, 1994.

6. Boumpas DT, Austin HA, Vaughn EM, et al: Controlled trial of pulse methylprednisolone versus two regimens of pulse cyclophosphamide in severe lupus nephritis. Lancet 340:741-5, 1992.

7. Lehman TJ, Sherry DD, Wagner-Weiner L, McCurdy DK, Emery HM, Magilavy DB: Intermittent intravenous cyclophosphamide therapy for lupus nephritis. J Pediatr 114:1055-60, 1986.

8. Austin HA, Klippel JH, Balow JE, et al: Therapy of lupus nephritis: controlled trial of prednisone and cytotoxic drugs. N Engl J Med 314:614-9, 1986.

9. Lui SL, Tsang R, Wong D, et al: Effect of mycophenolate mofetil on severity of nephritis and nitric oxide production in lupus-prone MRL/lpr mice. Lupus 11:411-18, 2002.

10. Bombardier C, Gladman DD, Urowitz MB, et al: Derivation of the SLEDAI: a disease activity index for lupus patients. Arthritis Rheum 35:630-40, 1992.

11. Ward MM, Pyun E, Studenski S: Mortality risks associated with specific clinical manifestations of systemic lupus erythematosus. Arch Inter Med 156: 1337-44, 1996.

12. $\mathrm{Vu} \mathrm{TV}$, Escalante A: A comparison of the quality of life of patients with systemic lupus erythematosus with and without end stage renal disease. J Rhematol 26: 2595-601, 1999.

13. Mok CC, Wong RWS, Lau CS: Lupus nephritis in southern Chinese patients: Clinicopathological findings and long-term outcome. Am J Kidney Dis 34:315-23, 1999.

14. Appel GB, Valeri A: The course and treatment of lupus nephritis. Ann Rev Med 45:525-37, 1994.

15. Bakir AA, Levy PS, Dunea G: The prognosis of lupus nephritis in African-Americans: A retrospective analysis. Am J Kidney Dis 24: 159-71, 1994.

16. Austin HA III, Klippel JH, Balow JE, et al: Therapy of lupus nephritis: controlled trial of prednisone and cytotoxic drugs. N Engl J Med 314:614-9, 1986.

17. Steinberg AD, Steinberg SC: Long-term preservation of renal function in patients with lupus nephritis receiving treatment that includes cyclophosphamide versus those treated with prednisone only. Arthritis Rheum 34:945-50, 1991.

18. Chan TM, Li FK, Wong RWS, Wong KL, Chan KW, Cheng IKP: Sequential therapy for diffuse proliferative lupus glomerulonephritis treated with sequential oral cyclophosphamide and azathioprine. Arthritis Rheum 46:1003-13, 2002.

19. Mok CC, Ho CTK, Chan KW, et al: Sequential therapy for diffuse proliferative and membranous lupus nephritis: cyclophosphamide and prednisolone followed by azathioprine and prednisolone. Nephron 71:321-7, 1995.
20. Mok CC, Ho CTK, Siu YP, et al: Treatment of diffuse proliferative lupus glomerulonephritis: a comparison of two cyclophosphamidecontaining regimes. Am J Kidney Dis 38:256-64, 2001.

21. Gourley MF, Austin HA III, Scot D, et al: Methylprednisolone and cyclophosphamide, alone ou in combination, in patients with lupus nephritis. A randomized, controlled trial. Ann Inter Med 125: 549-57, 1996

22. Sesso R, Monteiro M, Sato E, Kirsztajn G, Silva L, Ajzen H: A controlled trial of pulse cyclophosphamide versus pulse methylprednisolone in severe lupus nephritis. Lupus 3:107-12, 1994.

23. Belmont HM, Storch M, Buyon J, Abramson S: New York University/Hospital for Joint Diseases experience with intravenous cyclophosphamide treatment: Efficacy in steroid unresponsive lupus nephritis. Lupus 4:104-8, 1995.

24. Petri M: Infection in systemic lupus erythematosus. Rhem Dis Clin North Am 24:423-56, 1998.

25. Abu-Shakra M, Urowitz MB, Gladman DD, Gough J: Mortality studies in systemic lupus erythematosus. Results from a single center. I. Causes of death. J Rheumatol 2:1259-64, 1995.

26. Boumpas DT, Austin HA III, Vaugan EM, Yarboro CH Klippel $\mathrm{JH}$, Balow JE: Risk for sustained amenorrhea in patients with systemic lupus erythematosus receiving intermittent pulse cyclophosphamide therapy. Ann Intern Med 119:366-9, 1993.

27. Mok CC, Lau CS, Wong RWS: Risk factors for ovarian failure in patients with systemic lupus erythematosus receiving cyclophosphamide therapy. Arthritis Rheum 41:831-7, 1998.

28. Jayne D: Non-transplant uses of mycophenolate mofetil. Curr Opin Nephrol Hypertens 8:563-7, 1999.

29. Cross J, Jayne D: Mycophenolate mofetil in lupus nephritis. Lupus 9:647-50, 2000

30. Woywodt A, Choi M, Schneider W, Kettritz R, Gobel U: Cytomegalovirus colitis during mycophenolate mofetil therapy for Wegener's granulomathosis. Am J Nephrol 20:468-72, 2000.

31. Adu C, Cross J, Jayne DR: Treatment of systemic lupus erythematosus with mycophenolate mofetil. Lupus 10:203-8, 2001.

32. Gelber AC, Nousari HC, Whiley FM: Mycophenolate mofetil in the treatment of severe skin manifestations of dermatomyositis: A series of 4 cases. J Rheumatol 27:1542-5, 2000.

33. Epinette WW, Parker CM, Jones EL, Greist MC: Mycophenolic acid for psoriasis: A review of pharmacology long term efficacy and safety. J Am Acad Dermatol 17:962-71, 1987.

34. Allison AC, Eugui EM: Mycophenolate mofetil and its mechanisms of action. Immunopharmacology 47:85-118, 2000.

35. Carr SF, Papp E, Wu IC, Natsumeda Y: Characterization of human type I and type II IMP dehidrogenases. J Biol Chem 27286-90, 1993.

36. Nagy SE, Andersson JP, Andersson UG: effect of mycophenolate mofetil (RS-61443) on cytokine production: Inhibition of superantigen-induced cytokines. Immunopharmacology 26:11-20, 1993.

37. Mok CC, Lai KN: Mycophenolate mofetil in lupus glomerulonephritis. Am J Kidney Dis 40:447-57, 2002.

38. Hauser IA, Renders L, Radeke HH, Sterzel RB, Goppelt-Struebe M: Mycophenolate mofetil inhibits rat and human mesangial cell proliferation by guanosine depletion. Nephrol Dial Transplant 14: 58-63, 1999.

39. Ziswiler R, Steinmann-Niggli K, Kappeler A, Daniel C, Marti HP Mycophenolic acid: A new approach to the therapy of experimental mesangial proliferative glomerulonephritis. J Am Soc Nephrol 9:2055-66, 1998 
40. Dooley MA, Cosio FG, Nachman PH, et al: Mycophenolate Mofetil Therapy in Lupus Nephritis: Clinical Observations. J Am Soc Nephrol 10:833-9, 1999.

41. Chan TM, Li FK, Tang CS, et al: Efficacy of mycophenolate mofetil in patients with diffuse proliferative lupus nephritis. N Engl J Med 343:1156-62, 2000.

42. Petri M: Mycophenolate mofetil treatment of systemic lupus erythematosus. Arthritis Rheum 42S:S303, 1999.

43. Briggs WA, Choi MJ, Scheel PJ Jr: Successful mycophenolate mofetil treatment of glomerular disease. Am J Kidney Dis 31:213-7, 1998.

44. Figueiredo CP, Guedes LKN, Christmann RB, Gonçalves CR, Bonfá E, Borba EF: Eficácia do micofenolato mofetil na nefrite lúpica membranosa: experiência após um ano de uso. Rev Bras Reumatol 43S:S1, 2003.
45. Buratti S, Szer IS, Spencer CH, Bartosh S, Reiff A: Mycophenolate mofetil treatment of severe renal disease in pediatric onset systemic lupus erythematosus. J Rheumatol 28:2103-8, 2001.

46. Gesteira F, Montane B: Beneficial effect of mycophenolate mofetil (MMF) as maintenance therapy in children with severe lupus nephritis. J Am Soc Nephrol 13:15A, 2002.

47. Fu YF, Liu GL: Mycophenolate mofetil therapy for children with lupus nephritis refractory to both intravenous cyclophosphamide and cyclosporine. Clin Nephrol 55:318-21, 2001.

48. Barinstein L, Onel KB, Lehman TJA: Cyclophosphamide to treat severe pediatric lupus nephritis. Arthritis Rheum 48:260, 2003.

49. Hagelberg S, Lee Y, Bargman J, et al: Longterm followup of childhood lupus nephritis. J Rheumatol 29:2635-42, 2002. 